\title{
O CRAS em relação: profissionais e usuários(as) em movimento
}

\author{
Vinicius Tonollier Pereira, ${ }^{\star}$ Pedrinho Arcides Guareschi \\ Universidade Federal do Rio Grande do Sul, Porto Alegre, RS, Brasil
}

\begin{abstract}
Resumo
Este artigo parte de uma pesquisa de dissertação que procurou investigar as representações sociais de profissionais da psicologia que atuam em Centros de Referência de Assistência Social (CRAS) sobre os usuários deste serviço, objetiva demonstrar a existência de uma dimensão relacional entre profissionais e usuários, evidenciando assim possibilidades de transformações sociais e políticas tanto no contexto de vida dos destinatários da assistência social como também da própria psicologia inserida no Sistema Único de Assistência Social (SUAS). Entrevistou-se 21 psicólogas que atuam em CRAS. Dentre os resultados, percebe-se a vigência ainda de um legado histórico assistencialista e o quanto as relações entre profissionais e usuários(as) podem provocar possíveis processos de mudança social e política na vida desses sujeitos. Paralelamente, é possível pensar também o quanto a inclusão dessas e de outra dimensão, a ética, podem produzir avanços para a própria psicologia, tornando-a politicamente compromissada com as necessidades dessa população.
\end{abstract}

Palavras-chave: psicologia; assistência social; CRAS.

\section{CRAS in relations: professionals and users in movement}

\begin{abstract}
This article, part of a masters' research, sought to investigate the social representations built by psychologists working at Centro de Referência de Assistência Social (CRAS - Reference Center for Social Assistance) on users of the service. It aims to demonstrate the existence of a relational dimension encompassing professionals and users and, therefore, to evidence possibilities of social and political changes both in the context of life of recipients of social assistance and towards the field of psychology as practiced in Sistema Único de Assistência Social (SUAS - Universal System of Social Assistance). 21 psychologists working in CRAS have been interviewed. Among the results, it was noticed the presence of a historical assistentialism legacy and the extent to which relationships between professionals and users are likely to provoke social and political change processes. In parallel, it is also possible to think how the inclusion of such dimensions and the ethical one may lead to advances in the field of psychology, causing it to be more politically committed to the needs of that population.
\end{abstract}

Keywords: psychology, social work; CRAS.

\section{Introdução}

Este artigo, parte de uma pesquisa de dissertação, objetiva demonstrar a existência de uma dimensão relacional entre profissionais que atuam em Centros de Referência de Assistência Social (CRAS) e usuários(as) deste serviço, evidenciando as possibilidades de transformações sociais e políticas tanto no contexto de vida dos destinatários da assistência social, dentro do alcance dessa política, como também dos avanços possíveis à psicologia inserida no SUAS.

A pesquisa do qual este artigo faz teve como problema a questão sobre quais são e como se apresentam as representações sociais de profissionais da psicologia que atuam em CRAS sobre os(as) usuários(as) deste serviço, considerado a "porta de entrada" do SUAS, com um duplo objetivo: tanto mostrar quem são esses(as) usuários(as) para as participantes do estudo, como também desvelar, a partir dessas mesmas perspectivas, modos próprios e possíveis de se fazer psicologia nesse contexto. Dentre os resultados, identifica-se a existência de uma representação social relacional, que aposta na parceria entre profissionais e usuários(as) para possíveis processos de mudança social e política na vida desses sujeitos. Por relação, compreende-se o que Guareschi (2004) propõe para este conceito: algo que não pode ser sem o outro, que possui

\footnotetext{
^Endereço para correspondência: Universidade Federal do Rio Grande do Sul, Pró-Reitoria de Pesquisa e Pós-Graduação, Curso de Pós-Graduação em Psicologia. Rua Ramiro Barcelos, 2600 Sala 13 - Térreo - Santana. CEP: 90035002 - Porto Alegre, RS-Brasil.E-mail: viniciustonollier@hotmail.com, pedrinho.guareschi@ufrgs.br
}

um direcionamento intrínseco ao outro. É assim que se caracterizam as representações desses profissionais: concebendo os(as) usuários (as) em um contexto relacional, para além de uma dimensão individualista ou culpabilizadora que frequentemente responsabiliza unicamente esses sujeitos por suas condições de vida. Paralelamente, é possível pensar o quanto a inclusão dessas e de outra dimensão, a ética, podem produzir avanços para a psicologia, tornando-a politicamente compromissada com as necessidades dessa população.

\section{Sobre as representações sociais}

As representações sociais são tanto uma teoria, que se interessa pela forma como os saberes são produzidos e transformados na interação social; como um fenômeno, compreendendo ideias, valores e práticas inseridos em um contexto comunicativo e que constroem a realidade social (JOVCHELOVITCH, 2008), o que é de interesse neste estudo. Assim, as representações sociais se tornam um operador teórico imprescíndivel para esta análise. Deve se admitir que os fenômenos representacionais são mais complexos que o objeto de pesquisa construído a partir deles, ou seja, há uma simplificação quando passamos do fenômeno à pesquisa, e é justamente isso que permite sua inteligibilidade. Assim, utilizar as representações sociais é ter consciência que a pesquisa é uma aproximação da realidade estudada, nunca plena, mas aproximada, o que justifica sua utilização neste estudo. 


\section{Metodologia}

\section{Participantes}

Os participantes do estudo foram reunidos por conveniência, em CRAS de mais fácil acesso ao pesquisador, que reside em Porto Alegre, no Rio Grande do Sul. Para a coleta de dados, foram feitas entrevistas abertas, realizadas entre março e julho de 2012. No total, foram entrevistadas 21 psicólogas, todas mulheres. No decorrer do artigo, nas citações de suas falas, elas serão chamadas abreviadamente de P1 (participante 1), P2, P3 e assim sucessivamente, até a P21. As entrevistadas foram oriundas de 20 CRAS diferentes, de 9 cidades da região metropolitana de Porto Alegre e 5 da região central do Rio Grande do Sul, totalizando 14 municípios. Destes, de acordo com a classificação do SUAS (BRASIL, 2004), dois são de pequeno porte I (até 20.000 habitantes), três de pequeno porte II (de 20.001 a 50.000 ), dois de médio porte (50.001 a 100.000), seis de grande porte (100.001 a 900.000) e uma metrópole (mais de 900.000). A média de idade ficou em 32,5 anos, tendo a participante mais velha 58 anos e a mais nova 24 . O tempo médio de anos transcorridos após a conclusão de graduação é de 7 anos, sendo o maior tempo de 27 anos e o menor de 1 ano e 6 meses. Cerca de $70 \%$ se formaram em universidades particulares, sendo as outras $30 \%$ oriundas de universidades federais. O tempo total de trabalho em CRAS é em média de 1,8 anos. O maior tempo de trabalho em CRAS foi de 6 anos e 6 meses e o menor de 4 meses. O tempo médio de carga horária semanal foi de 30 horas, sendo as maiores de 40 horas, e a menor de 16, discrepante dos dados do Censo SUAS 2009 (BRASIL, 2011), que trazem que $51 \%$ dos profissionais com ensino superior cumprem 40 horas semanais. Quanto ao vínculo empregatício, a maioria, 13 delas, eram servidoras estatutárias, enquanto 8 tinham contratos temporários, o que está acima da média apresentada pelo Censo SUAS 2010 (BRASIL, 2010), que indica que apenas $35,6 \%$ dos servidores com ensino superior nos CRAS do país são concursados.

Sobre as participantes da pesquisa, a presença única de mulheres está em consonância com os dados de Macedo et al. (2011), que indicam que do total de 8.079 psicólogos(as) que atuavam em CRAS no Brasil em 2011, 89,6\% são mulheres, evidenciando a preponderância do público feminino. Isto tem a ver com a maior presença feminina do que masculina nos cursos de psicologia, e também nos de serviço social, que fazem com que os serviços da política deassistência social sejam executados predominantemente por mulheres. No Rio Grande do Sul, segundo os mesmos autores, em torno de 400 psicólogos(as) atuam em CRAS, sendo relevante que se tenha entrevistado cerca de $5 \%$ destes(as) trabalhadores para este estudo (21 profissionais), embora não se esteja interessado nos números de opiniões nem em generalizações absolutas dos achados. Esta significância apenas indica que se tem uma boa gama de representações a se explorar nos resultados desta pesquisa.

Fractal, Rev. Psicol., v. 28 - n. 1, p. 102-110, 2016

\section{Procedimentos para a entrevista}

Antes das entrevistas, as participantes tomaram ciência do Termo de Consentimento Livre e Esclarecido, assinando-o ao concordar em participar da pesquisa, sendo informadas da possibilidade de desistência a qualquer tempo. Um tópico-guia auxiliou na entrevista, tentando, contudo, preservá-la o mais livre possível. O tópico-guia foi composto por cinco itens: 1) quem são os usuários do CRAS e como caracterizá-los?; 2) como são as famílias usuárias do CRAS e como caracterizálas; 3) como é a vida desses sujeitos (em termos de rotina e cotidiano, o que ia sendo explorado a partir de mais perguntas de acordo com o que era trazido pelas entrevistadas); 4) há aspectos dos usuários que podem ser vistos como obstáculos para a efetivação das propostas do CRAS/SUAS e, se sim, quais são eles; e 5) se há aspectos dos usuários que podem ser vistos como positivos e que contribuam para a efetivação da proposta do CRAS/ SUAS e, caso existam, quais são eles.

A definição por 21 entrevistas obedeceu ao critério de saturação indicado por Bauer e Aarts (2008), no qual as entrevistas vão sendo realizadas, produzindo diferentes representações e um bom volume de dados, até que a inclusão de novos participantes não acrescente mais tantos dados inéditos ou significativamente relevantes, produzindo, em sua maioria, discursos recorrentes. Ou seja, mais entrevistas não levariam necessariamente a um entendimento mais detalhado. Bauer e Aarts (2008) indicam que o número entre 15 e 25 entrevistas individuais é o máximo possível para uma criteriosa análise, o que está de acordo com este estudo.

\section{Procedimentos para análise das entrevistas}

Posteriormente, todo o material levantado nas entrevistas foi submetido à análise de discurso, conforme proposta por Gill (2008). Para a autora, não há um roteiro delimitado para tanto, mas sim etapas que podem ser mais ou menos estruturadas. Segundo a autora, o primeiro passo é a transcrição das entrevistas, a partir dos registros literais das falas. A manutenção dos registros literais das fontes no decorrer do trabalho - ao invés da seleção de pequenos recortes que apenas legitimam o que diz o autor - foi uma proposta mantida nesta pesquisa, baseada na ideia de que o registro literal indica confiabilidade, como afirmam Gaskell e Bauer (2008), já que dão margem para diferentes interpretações, permitindo ao leitor que aceite ou refute os pontos de vistas explorados.

Após a primeira parte, Gill (2008) relata que se inicia a análise propriamente dita, através de uma leitura que seja capaz de tornar o familiar estranho, a partir de um espírito cético, atento ao contraditório e ao detalhe. Feito isso, passa-se à codificação, em um movimento de mergulho no material, que desta vez torne o conteúdo familiar, para que seja possível a organização em campos temáticos, mais gerais no início. Em seguida, acontece uma análise mais profunda, em que se refinam as primeiras análises. Embora o material seja categorizado, não significa que ele não suporte contradições e fragmentos. Pelo contrário, já que as representações sociais são totalmente afeitas à ambivalência. 


\section{Resultados}

Os resultados apontam para a vigência ainda de uma cultura assistencialista - legado que acentua o papel dos(as) profissionais na possível desarticulação dessa trama histórica da assistência social - e para a importância da dimensão relacional na produção de avanços, tanto na vida dos usuários como para a psicologia, enquanto ciência e profissão. Porém, cabe salientar que outras dimensões, para além do alcance dos trabalhadores, como complexos aspectos políticos, sociais e culturais, também contribuem para a manutenção e reprodução do assistencialismo em nosso país.

A partir dos sentidos produzidos pela pesquisa, organizou-se quatro campos temáticos. No primeiro, o sentido fortemente presente é o da cultura assistencialista, que ainda captura os(as) usuários(as), e quais as concepções das entrevistadas sobre o papel da psicologia na desconstrução desse legado histórico. O segundo aborda a resistência dos(as) usuários(as), compreendida positivamente dentro desse contexto histórico assistencialista. No terceiro item, são destacadas falas que remetem aos bons vínculos formados entre profissionais e usuários(as), o que é essencial para a efetividade das ações no CRAS, conforme as entrevistadas. E, por fim, abordamse falas que evidenciam o quanto já há uma mudança em movimento, a partir do trabalho e das relações firmadas entre os(as) usuários(as) e os(as) profissionais.

1. "As pessoas se acostumaram em pedir e aqui o trabalho é de desconstruir isso": a cultura assistencialista e o papel do profissional em uma possível desconstrução

É quase unânime entre as entrevistadas que existe ainda uma cultura assistencialista que segue capturando os(as) usuários(as) e os(as) engendrando em uma lógica própria de funcionamento que caracterizou e ainda caracteriza a assistência social.

Para algumas profissionais, sendo o SUAS uma política em construção, está, entre os objetivos do trabalho, a desconstrução do longo histórico de assistencialismo vinculado à área, bem como o rompimento com a ideia de tutela e governo dos profissionais sobre a vida dos sujeitos. Para isso, um dos principais papéis a ser exercido pelos trabalhadores é o de mostrar caminhos alternativos para as mudanças. Isso se dá por diversos meios: através do acesso à documentação; de uma escuta qualificada que leve ao questionamento e à reflexão; ou com intervenções diretas sobre aspectos sobjetivos, pois embora o assistencialismo seja um problema social que não tem sua gênese nos sujeitos, nem cabe a eles a responsabilização única por sua superação, é neles que se observam suas facetas e consequências (SAWAIA, 2012). Assim, nesse cenário, a mudança é vista como possível, embora de forma lenta e gradual.

Com a instalação do CRAS, mudando a política de assistência social na cidade, mudou inclusive o que se pensa sobre o nosso trabalho. E eles vêm nos cobrando isso. Dizem que vão lá no prefeito reclamar, que não estamos fazendo nosso trabalho, ou vão lá no prefeito pedir, que a prefeitura não ajuda mais, e é dificil quebrar essa questão da tutela. Era uma política assistencialista, era a característica da cidade, a característica da política no Brasil por muito tempo, então desconstruir isso pra construir outras possibilidades demora. [...] Por exemplo, quando tu consegue fazer um trabalho eles agradecem, 'ah muito obrigado por tua ajuda'. Também é na mesma lógica, nós estamos exercendo um direito, eles também não têm a condição de sujeito político, com direitos, de ver que isso é um direito deles. [...] Eu ainda estou aprendendo sobre o CRAS, ainda estou aprendendo sobre as possibilidades do psicólogo aqui, [...] mas eu percebo algumas características, que acho que são ranços de politicas da cidade. Que as pessoas se acostumaram em pedir e aqui o trabalho é de desconstruir isso. P16

A cultura geral do município e das pessoas é muito assistencialista ainda. Da secretária, das pessoas, distribuirem caminhão de verdura. Então elas vinham aqui para os grupos do Bolsa, do Bolsa e não do CRAS, e recebiam [...] dois quilos de arroz e dois quilos de leite em pó. Então elas vinham muito esperando isso. [...] Tem uma cultura bem assistencialista. Infelizmente as pessoas acabaram vinculando o CRAS muito a isso, e a gente está tentando desconstruir assim né. P11

O usuário está conhecendo o que é o Centro de Referência de Assistência Social, ele está conhecendo que nós estamos aqui pra que ele consiga acessar os direitos dele né, e não pra tutelá-lo, e eles têm considerado, aquelas famílias que acessam mais freqüentemente assim, que já sabem dessa diferença, e isso é muito positivo né. P6

Os principais obstáculos que eu vejo para a efetivação do SUAS não vêm dos usuários, vêm da implantação dos serviços mesmo né. Eu acho que da parte dos usuários talvez essa concepção assim, mas eu entendo isso como uma tarefa do SUAS, de trabalhar em cima dessas concepções, relações de dependência, desnaturalizar alguns funcionamentos, refletir né, ser crítico em relação a isso. [...] Eu tenho trabalhado muito com a lógica dos pequenos passos. [...] Se hoje uma mãe conseguiu [...] um documento que faltava né pra familia, bom esse documento significa algo maior pra essa família, vai dar acesso para alguma coisa, então foi uma conquista importante que precisa ser bem valorizada [...] pra ela saber que ela é capaz de outras conquistas. P2

Questões culturais a gente assim até tenta desmistificar um pouco, mas é uma cultura muito enraizada né. Então é difícil uma cultura com anos de sequência né, inserido ali num contexto de crime, violência, de pobreza né, é dificil tu querer vir agora e implantar pra eles uma vida nova. Isso não existe. O que existe é um trabalho a longo prazo com alguns retornos no presente. Alguns são pessoas que respondem mais rapidamente ao trabalho que tu desempenha com eles, esse acompanhamento né. Mas tem outros que não, que têm uma dificuldade maior. P7

Eu entrei aqui e minhas colegas diziam essa pessoa todo mês vem pedir. E eu me perguntava por que então não se constituía um outro sujeito, não mais de vir pedir, mas de que ele então repense isso. Por que ele está todo mês vindo pedir? [...] Por que ao invés de constituir outra subjetividade, tu reforça uma de dependência, tutela? Então quando tem esses casos que elas estão acostumadas 
eu acabo intervindo nisso, eu evito dar, e então começo a conversar, sobre a trajetória dessa pessoa no CRAS. [...] Eu tento conversar outras coisas, sobre o que é o CRAS, qual nosso trabalho, o que é a política de assistência social, quais são os direitos dessa pessoa e às vezes vai vindo, em alguns atendimentos aparece outras coisas, mas sempre vem naquele momento, e depois não voltam. [...] É dificil de quebrar isso. P16

A gente tem que conscientizar, trabalhar principalmente com a questão da autonomia, e ai esse principalmente o enfoque das oficinas né, poder capacitar o pessoal do Bolsa-Família, poder trabalhar a autonomia, a dignidade, a autoestima, enfim. [...] A gente tem trabalhado muito nessa perspectiva né, de promover a autonomia, de trabalhar a autoconfiança, trabalhar com a auto-estima, pra que eles possam superar certas questões culturais [...] desse paternalismo né. P19

A grande quantidade de falas que versam sobre o tema evidencia o quanto a representação sobre uma característica assistencialista presente nos(as) usuários(as), nos serviços e no contexto da assistência social ainda está presente. O que muda um pouco é o modo de compreender essa questão. Muitas profissionais falam a partir de uma perspectiva sóciohistórica abrangente, cientes do longo processo tutelar e assistencialista que pairou sobre a população pobre do país durante longo tempo, em que não havia mesmo uma política, mas práticas benevolentes e caridosas dos mais ricos em favor dos mais pobres. Nessa lógica, cabe aos profissionais o trabalho de desconstrução desse legado ao propor a implementação de uma política garantidora de direitos. Por outro lado, observa-se que na fala de outras profissionais parece haver indícios de uma lógica mais individualista, às vezes até produzindo uma culpabilização individual pelo assistencialismo, desconsiderando-o como problema social e histórico do país. Nessa lógica, acredita-se que sua superação se daria mais a partir de um trabalho individual, sobre a autoestima, por exemplo. Mas de maneira geral, compreendese que nesse campo temático há uma linha condutora que tem como sentido o entendimento do assistencialismo enquanto cultura histórica do país, e de como as relações entre profissionais e usuários(as) têm o poder de ir modificando essa realidade.

Nesta persperctiva, sai a noção de caridade e assistencialismo para entrar a concepção de direito, ideia essa ventilada por muitas falas acima e que exige, primeiramente, o próprio conhecimento desses direitos - desafio à psicologia que, de modo geral, não transita muito por esse tema em suas formações - e, segundo, um novo arcabouço teórico que fortaleça práticas que viabilizem a autonomia e protagonismo dos(as) usuários(as) em suas vidas, objetivo esse também bem visibilizado pelas entrevistadas. Essas possibilidades são pistas de caminhos que podem intensificar o processo de desconstrução da cultura assistencialista, onde o protagonismo não pertence somente aos(às) profissionais, mas recai na relação entre eles(as) e os(as) usuários(as).
Sobre a operacionalização prática disso - a desconstrução do assistencialismo a partir da relação entre profissionais e usuários(as) - Ximenes, Paula e Barros (2009) afirmam que a atuação da psicologia nos espaços de vida comunitária não se justifica pela extensão do serviço psicológico nos seus moldes tradicionais, mas sim pela premissa de que as comunidades possuem redes interativas que ativamente agem na complexa construção de pessoas e grupos que ali vivem. É isso que pode se tornar base para uma práxis psicológica que opte por uma perspectiva relacional, como apontado por Guareschi (2004), onde a pessoa é uma mas ao mesmo tempo é outras, isto é, não pode ser concebida fora das múltiplas relações que estabece na vida, valorizando assim as singularidades das diversas formas de vivência da vulnerabilidade social. Esse trabalho só se torna possível a partir de encontros dinâmicos, que privilegiem o compartilhamento dialógico dos saberes e a problematização de conhecimentos e processos já cristalizados, para que assim se potencialize a ação de todos os atores envolvidos. Ou seja, que conjuntamente profissionais e usuários(as) possam construir novas e outras possibilidades diferentes das já existentes, sem que esses meios sejam apenas apontados de antemão, mas construídos em parceria no "mundo da vida" contextual onde acontecem esses encontros.

Portanto, é de se esperar que os(as) usuários(as) se apresentem ainda capturados pelo assistencialismo, devido ao seu longo histórico no país, mas, mesmo quando aparecem com solicitações de pedidos, é preciso estar atento para a legitimidade de muitas dessas reivindicações, pois alimentação, renda e moradia digna, por exemplo, são direitos constitucionalmente garantidos em nosso país, embora não assegurados. Por isso, cabe aos profissionais o devido cuidado no acolhimento e acompanhamento dessas demandas, podendo entendêlas nao como benesses, mas como direitos legalmente garantidos que nao estão sendo plenamente assegurados.

2. "Será que eu iria também?": uma compreensão positiva da resistência

Neste campo temático se aborda a resistência dos(as) usuários(as) em aderir às propostas dos(as) profissionais e dos serviços. Porém, isso não é visto apenas em uma lógica individualizante ou culpabilizante como se aponta em outra pesquisa (PEREIRA; GUARESCHI, 2014) mas sim de maneira positiva e empática, já que algumas profissionais entrevistadas conseguem se aproximar da perspectiva dos(as) usuários(as) e percebem que a dificuldade de adaptação às intervenções não é feita deliberadamente, mas sim devido a dificuldades originadas nos contextos onde estão inseridos(as), sejam eles econômicos, sociais, políticos, culturais ou históricos. Isto é, nas falas abaixo não existe uma responsabilização dos(as) usuários(as) por sua resistência, mas o entendimento desta a partir das situações em que vivem, denunciando mais uma vez a existência de uma cultura assistencialista que se torna entrave para os avanços no campo. 
Nos usuários, eu sou daquela opinião de que a gente primeiro olhe pro que têm de recursos, de ofertas, pra depois dizer assim "ah ninguém adere". Comecei falando né ninguém adere. Mas eu sempre acho que o problema não é deles, que a gente têm que ver por que eles não aderem, o que eles querem fazer aqui no CRAS. P9

Uma questão que a gente tem bastante dificuldade é que a adesão ao acompanhamento, às vezes eles não se sentem no direito de usufruir do que o CRAS oferece, de participar mais ativamente de grupos ou de oficinas. A gente sempre tem que fazer muito esforço pra mobilizar as pessoas, pra elas chegarem até o CRAS. Então é muito mais fácil pra eles às vezes virem pedir uma cesta básica do que vir tratar às vezes de uma questão, de um conflito familiar que tu possa ajudar essa familia a se fortalecer e poder fazer algo. $P 9$

A nossa particularidade em termos de cultura é a resistência no sentido de poder trabalhar alguma coisa de mudança, então tem essa dificuldade, [...] de eles poderem mudar a perspectiva de vida, de romper com aquela situação, de poder almejar outras situações melhores. [...]Mas dai também entra outro sistema que interfere nisso, político, econômico, social, mas acho que o trabalho do CRAS é esse: buscar essa mudança. P21

Acho que tem (resistência), mas que não é culpa deles, é da ordem cultural, histórica do Brasil, acho que tem essa desigualdade social histórica [...] tem toda essa coisa histórica que no município é muito forte [...] faz com que as pessoas sejam passivas. A gente abre o grupo aqui, às vezes tenta pescar uma história, vai ter uma oficineira, vai ter um curso, um link material pra engatar o sujeito ai depois ele vê que vai ter outras coisas, que vai gerar renda, e ele não vai sabe, às vezes acontece muito isso assim, uma certa conformidade com essa situação. [...] Muitas desistem, porque também acho que em algum momento desistiram delas, senão elas não estariam nesse lugar, não precisariam de todo esse aparato público que se construiu pra suprir algo histórico. P12

Eu vejo como muito positivo às vezes inclusive esses movimentos de suposta resistência, porque assim, muitas vezes a política pública aponta um caminho, vamos supor, da construção civil, se emancipar pela via da construção civil, oferecer cursos nessa área. Então a gente sabe também que têm toda uma questão macropolítica por trás, do mercado da construção civil, agora a gente vai ter essa questão de copa do mundo, enfim. E daqui a pouco vem um discurso enlatado que a gente têm que oferecer pra essas mulheres, pois afinal de conta as mulheres podem estar na construção civil tanto quanto os homens, enfim, se a gente escuta com os ouvidos desatentos a gente compra essa ideia com força e fica empurrando às vezes coisas que as pessoas não precisam e não querem né. Então eu particularmente até acho super interessante quando a gente oferece alguma coisa nessa linha e dizem "ah eu não quero saber disso, eu não quero, eu quero outra coisa ou eu quero poder escolher, ou eu quero ser manicura, ou eu quero então costurar né", fazer o quê. E isso tem que ser entendido, tem que ser aceito. Então eu acho isso que é muito bom que o usuário apresenta. A gente vem com uma ideia dele, que é colocar ele dentro de uma caixinha e ele vem e nos surpreende. Mas só tem que estar atento pra escutar isso como algo positivo, e não pensar assim "ah fulana não quer nada com nada, ela não quer o curso de construção civil porque quer se encher de filhos". Bom, essa é uma leitura, só que é o tipo de leitura que não ajuda né. É preciso entender como algo positivo que bom, ela tem o desejo dela, o querer dela, querer sair da dependência da forma dela. P3

Percebe-se que muitos significados presentes nas falas apontam para uma compreensão positiva da resistência, não como uma oposição aos serviços, mas sim como um desejo, uma possibilidade de subjetivação ao seu modo, tendo liberdade em escolher seus meios próprios para uma mudança de vida, inclusive opções alternativas àquelas oferecidas pelos profissionais, como fica claro principalmente na última fala acima. Hillesheim e Cruz (2012), baseadas no conceito de biopolítica de Foucault, demonstram como a assistência social pode compor uma ampla estratégia de normalização da população pobre, compreendendo uma forma de regulação do Estado sobre a vida, moldando assim determinadas formas de subjetividade. No entanto, sempre existem maneiras de resistência a essas estratégias, embora só em alguns casos sejam vistas como tal. Neste campo temático, observase que várias entrevistadas conseguem ter esse tipo de compreensão, ao ver na resistência formas plurais de "levar a vida", e não somente no sentido negativo de não aderência aos serviços.

Para Lasta, Guareschi e Cruz (2012, p. 64), entre os desafios da psicologia no CRAS está a capacidade de poder pensar o sujeito psicológico para além de alguém a ser normalizado e institucionalizado pela política de assistência social, "sujeitos apropriados ao Estado" e definidos somente pela vulnerabilidade e pobreza, mas vistos como sujeitos nos quais também existe vida, contradições, passividades e resistências. Isto é, que diferentes olhares possam ser lançados, capazes de ir para além de condições de carência e impossibilidades ou de uma via única de mudança imposta pelos profissionais, mas que se interessem pelas formas de resistência e de produção de potência de vida, que, felizmente, também já se fazem presentes na assistência social como se observa nos sentidos aqui produzidos.

Assim, é importante que os profissionais consigam fazer essas leituras "positivas" da resistência, não como uma inadequação dos(as) usuários(as), mas também como formas de ações autônomas e protagonistas de seus destinos, escolhendo seus meios próprios de lidar com as situações.

\section{Relações delem família: a possibilidade de modos diversos de organização}

Neste campo temático são apresentados significados flexíveis e tolerantes sobre os modos diversos de relações familiares, diferentes de compreensões patologizantes sobre as desestruturas ou disfunções da família, como indicado em outra pesquisa sobre este tema (PEREIRA; GUARESCHI, 2014). Contrapondo-se concepções ideais de família, as representações aqui presentes trazem uma visão crítica sobre seu funcionamento, aceitando modos diversos de organização, compreendendo-as dentro de 
um contexto social adverso. Assim, o trabalho no CRAS, longe de tentar adaptá-las, busca fundamentalmente entendê-las, respeitá-las e tentar intervir a partir de uma compreensão empática.

Fica difícil falar dessa organização assim, porque muitas vezes quando a gente tem essa discussão com a rede assim, "ah porque tu tem que dar conta, porque essa família é extremamente desorganizada, porque a casa deles é suja, porque não sei o quê, porque as crianças vão sujas pra escola". Bom, tu entende que dentro daquela dinâmica familiar é a forma de eles se organizarem. [...] Tem muitas questões bem complicadas que permeiam as histórias das nossas famílias. P10

Não existe muito aquela coisa assim de configuração familiar tal qual era visto um tempo atrás né, pai, mãe e filhos tudo bonitinho, isso já não existe mais, é uma nova configuração da família. [...] A família existe de uma maneira muito diferente, a gente tem que estar instruida pra trabalhar com essa nova configuração da família, não é mais a mesma como a gente via antigamente assim, muito redondinha, muito certinha. E tu tem que criar com eles estratégias para poder dar conta das dificuldades. É a maneira como eles encontram de se configurar como família né. P7

Uma mãe que diz assim "ah mas eu não bato tanto nos meus filhos, como eu vejo a vizinha batendo", por exemplo. "Eles não podem reclamar, porque eles têm o que comer, comem o que querem, quando querem, $e$ eu vejo gente que é muito pior". Então aqueles são os valores dela, ela acha que está educando os filhos da maneira certa, e que assim está certo. P18

Têm algumas pessoas, não um grupo especificamente, que têm muitas dificuldades financeiras e ai elas saem pra catar de manhã pra comprar um quilo de arroz pro meio dia e de tarde pra de noite. Então um dos turnos as crianças ficam soltas né. E isso é uma coisa que eu me pergunto: será que a gente tem que exigir, claro o ideal é que elas sejam mãe dessas crianças, mas elas não estão sendo mãe procurando algo pra colocar na barriga das crianças? Isso é uma coisa que me pergunto. P14

Tem gente que fala de família desestruturada, eu acho errado esse conceito, eu acho que de alguma forma eles sempre se estruturam, eles funcionam diferente daquilo que a gente espera pra ter uma qualidade de vida. P20

A partir das falas, percebe-se uma tolerância a modos de organização diversos, onde há alguns movimentos nos quais as psicólogas tentam se colocar no lugar dos(as) usuários(as), questionando uma organização familiar padrão ou esperada. Para Mioto (2010), uma concepção de família nessa linha alternativa pode contribuir para a assistência e proteção ao invés da penalização das famílias por suas impossibilidades. Além disso, desvencilhar-se das distinções entre famílias capazes ou incapazes, normais ou patológicas, pode permitir aos(às) profissionais construir novos olhares sobre as famílias e novas relações com elas e entre elas e os serviços.

Segundo Fávero (2007), a precariedade das condições de vida contribui para que se ampliem outras formas familiares, o que é plenamente entendido por diversas profissionais, como evidenciam os recortes acima. Em certas situações se torna impraticável a intimidade, a relação conjugal e a centralidade da criança - características atribuídas a uma família padrão moderna - quando a luta pela sobrevivência se impõe como fator central.

Para Couto et al. (2010), os arranjos familiares diversos sempre foram característicos das famílias pobres, tratados por longo tempo como distorções a serem corrigidas pelos técnicos sociais. Seu caráter protetivo só pode ser exigido se a própria família está protegida e cuidada ao menos nas suas necessidades básicas, o que não condiz com a situação de milhares de casos do país. Assim, há um forte caráter moralista e disciplinador que deve ser eliminado do trabalho no SUAS, como parece que já vem ocorrendo em certas situações, como aqui observado, embora seja necessário ainda muitos avanços, já que outras pesquisas indicam resultados significativos sobre a patologização dos arranjos familiares. Essas mesmas autoras alertam também que se tome o devido cuidado com o risco de se enaltecer a subjetividade das famílias e assim perder de vista a identidade coletiva dessas pessoas.

Por fim, essa compreensão ampliada em torno do conceito de família, reconhecendo como legítimas outras formas de relações, está em consonância com a proposta do SUAS. Para realizar o trabalho social com famílias de forma a atender os pressupostos da Política Nacional de Assistência Social, é indispensável que se ultrapasse o conceito da família "ideal", assumindo a família "real": lugar de cuidados, afetos, e também de conflitos, diferenças e dificuldades. Nessa direção, é importante compreender que a família é uma instituição social que não pode ser vista como estática, definitiva e fechada. Ao contrário, é uma construção a partir de critérios e contextos históricos, sociais, econômicos e culturais específicos. Ou seja, uma complexa e emaranhada rede de relações, situadas em contextos com múltiplas variáveis adversas, mas também com possibilidades e potencialidades, rompendo assim com posturas individualistas ou familiaristas que as estigmatizam e culpabilizam (BRASIL, 2012).

\section{Relações entre profissionais e usuários(as): bons vínculos}

Neste campo temático são apresentados sentidos que remetem às possibilidades de formação de um bom vínculo entre profissionais e usuários(as), o que é fundamental para a realização do trabalho. Pela organização das falas, vê-se que o processo talvez comece em um primeiro movimento, de respeito da comunidade pelo trabalho dos(as) profissionais, seguido de uma formação de um verdadeiro vínculo afetivo, que torna o trabalho possível.

É um usuário e uma usuária que dificilmente vêm aqui assim pra fazer "barraco" ou coisas assim. Já enfrentamos situações assim, mas dá pra contar nos dedos. São pessoas que nos respeitam aqui e estão começando a conhecer nosso trabalho. [...] Tem gente chegando, acessando, conhecendo o serviço. [...] Na medida que estão conhecendo o serviço, estão respeitando o trabalho que a gente faz. Nunca tive problemas de caminhar por aqui. Lá mesmo dentro do 
território [...] nunca tive problema de pisar lá dentro, de caminhar por lá, então eles respeitam o trabalho que a gente está fazendo né. É muito legal. P6

A confiança que eles depositam na gente, de trazer às vezes coisas muito dificeis, muito pesadas pra eles, e se autorizar a dividir com um estranho, com alguém que está ali pra ouvir, mas que não pertence às vezes tanto a comunidade [...] Quando tu percebe que eles confiam em ti, se reportam a ti, isso é um retorno muito positivo, acho que isso ajuda a gente a cada vez a pensar mais, estudar mais também. P9

Tem os que aceitam, os que gostam de vir no CRAS, os que querem participar de todas as oficinas que são oferecidas, os que estão sempre aqui [...] que quer participar, que quer fazer tudo. [...] A maioria é muito aberta assim, muito receptiva, tudo que tu oferece eles gostam, a maioria é assim. E eles se sentem em casa, eles passam aqui na frente, eles chegam. [...] A equipe fica muito feliz quando eles vêm, porque a maior dificuldade é quando os usuários não vêm. Então quando eles vêm a gente fica bem contente. P18

Eu achei que iria ter muito trabalho pra conseguir construir vínculos né, desenvolver entre eles, e eu vejo que não, que não tem tanta dificuldade assim, que eles são realmente muito dedicados e as famílias que eu trabalho [...] não tenho dificuldades quanto a isso. P5

A questão de eles procurarem, de poderem se vincular aos profissionais, de confiarem nos profissionais, pra poder melhorar, tentar sair dessa situação de problemas que muitas vezes eles vivem. P21

Percebe-se pelos sentidos produzidos o quanto existem situações de boa vinculação entre profissionais e usuários(as) e comunidades. Isso remete ao que MartinBaró (1996) define como o mais importante saber para a psicologia: o saber inserido na práxis cotidiana, diferente do saber explícito e formal, mas sim o que é muitas vezes implícito e inconsciente, que pode tanto ser adequado ou não a realidade objetiva, humanizar ou não as pessoas e permitir ou não a elas a possibilidade de manter o controle sobre sua própria existência. E, para fundamentar tal saber, é preciso mesmo vivenciá-lo, o que se dá a partir do estabelecimento de relações com as pessoas no cotidiano.

Esses significados aqui presentes contrastam com qualquer discurso de não aderência dos(as) usuários da assistência social, o que mostra que eles(as) também acessam os serviços e se vinculam aos(às) profissionais. Nessas relações, abrem-se possibilidades para encontros genuínos com o outro e com o mundo, sem opressores ou oprimidos, mas pela via do diálogo e do ideal de comunicação entre iguais (MARTIN-BARÓ, 1996). A ação comunicativa remete à dimensão ética, como propõe Guareschi (2004), que, ao entender ética como relação, pressupõe sempre a consideração da dimensão do outro.

É nessa lógica relacional e de proximidade dos(as) psicólogos(as) com os(as) usuários(as) que pode haver um verdadeiro encontro, em que os(as) profissionais podem (re)conhecer sujeitos que têm sentimentos, valores, ideias e modos próprios de se relacionar com o mundo, em uma subjetividade construída a partir das milhares de relações estabelecidas, valorizando assim suas experiências subjetivas para a possibilidade de transformação da pessoas, do meio social onde vivem (CONSELHO FEDERAL DE PSICOLOGIA [CFP], 2008) e também da própria psicologia.

\section{Relações de sucesso: mudanças em movimento}

Mesmo que as mudanças na vida dos(as) usuários(as) sejam vistas como processos lentos e graduais, alguns representações investigadas por este trabalho - das intervenções e relações estabelecidas entre profissionais e usuários(as) -parecem estar se materializando na realidade dos serviços. Conforme grande parte das entrevistadas, existem consequências palpáveis e positivas geradas pelos encontro entre profissionais e usuários (as), pois muitos(as) dessas pessoas estão conseguindo buscar novas alternativas de vida, avançando a partir do acompanhamento que recebem no CRAS. Nota-se em muitas falas das participantes da pesquisa que esse é um processo recíproco, já que tanto os(as) profissionais devem fazer sua parte, mostrando os caminhos possíveis para as mudanças, como também os(as) usuários(as) devem ser co-responsáveis pelo sucesso das intervenções.

Eles aceitam o trabalho da gente, alguns a gente consegue fazer com que eles pensem, que busquem as coisas pra eles. [...] Eles buscam, eles concordam, eles refletem né e eles vão procurar coisas alternativas, sabe. Como eu te disse, têm alguns que são receptivos com o que a gente leva. [...] Que tem essa troca né, que eles dão esse retorno, que eles vão procurar um emprego, que eles vão buscar o que eles vieram buscar aqui que a gente só orientou. $P 8$

São pessoas que precisam participar desse processo de transformação. A gente tenta ao máximo co-responsabilizar eles, com ações, com combinações que a gente faz né, pra que eles também se apropriem desse processo e que não seja uma coisa de eles ficarem sempre dependentes assim. Mas entendo que são processos muito longos, não é coisa de dias ou meses assim, pode levar anos. P2

E na medida que essa pessoa está envolvida com essa proposta de trabalho de melhora, as coisas acontecem. Se a pessoa não quer a gente sozinha não faz nada. [...] A gente oferece caminhos, mas tu tem que dar conta de ir por esses caminhos pra buscar o melhor pra ti. Caso contrário não dá. Eu não tenho a função, a gente enquanto assistência não tem como ir lá na casa dela e dizer "olha, faz isso, isso, isso". Não. A gente aponta caminhos e ajuda a criar estratégias, mas quem vai por esse caminho é tu, que vai escolher e arcar com as consequências. P7

Hoje teve um caso que foi muito bom, uma senhora ligou pra cá e disse "olha, eu estou ligando pra saber como é que eu faço pra cancelar meu Bolsa-Família, eu consegui um emprego então agora eu não preciso mais, eu queria passar pra alguém que precise mais do que eu”. Então puxa né, é nessas horas que tu ve que teu trabalho está dando certo né, que tu está conseguindo conscientizar, então nessas horas tu vê que está valendo a pena. P10

Porque às vezes a gente acha né "ah Bolsa-Familia eles querem cada vez ter mais filhos pra aumentarem o BolsaFamília". Tu ta vendo assim que as pessoas não têm isso, elas têm noção de que 32 reais não faz nem cócegas no 
que um filho demanda, não só financeiramente, mas o que um filho demanda em todos os sentidos. Tem muita gente que têm esse preconceito. [...] Mas eu acho que na medida que o Bolsa-Família nos dá essa necessidade de um contato próximo com a família, esse acompanhamento sabe com a família, eu acho que realmente a gente vai garantir que essa geração que está obrigatoriamente indo na escola agora, vai ser uma geração que vai poder pensar diferente, ter uma vida diferente da dos pais deles, que não tinham o Bolsa-Família. P2

Têm alguns, não são vários, mas já teve casos de pessoas que necessitaram de acompanhamento, utilizaram, foram beneficiadas dos programas e conseguiram superar as dificuldades, e hoje não precisam mais da assistência. Tem casos aqui de pessoas que iniciaram conosco e conseguiram fazer uma faculdade, tão trabalhando, encontram a gente $e$ vêm conversar: "que bom quando eu precisei encontrei vocês, hoje quero te dizer que to bem, que to trabalhando". P1

E acho que a maioria dos usuários, se tu tiver um pouco de boa vontade, insistência, paciência, sei lá, acho que eles têm essa disponibilidade pra fazer algo diferente, mas algo diferente que eles não conhecem, e que a gente conhece muito pouco. A gente vem pra ser técnico de um espaço onde a gente muitas vezes não conhece a politica pública né e tampouco a gente conhece o espaço né. Eu acho que o usuário ele está muitas vezes disponível pra ouvir o que tu está falando e pra falar também. Pra se construir isso em conjunto e acho se isso der certo se efetiva sim. P4

Percebe-se que construção de novas possibilidades e avanços na vida dos(as) usuários(as) do CRAS é um processo em movimento, sem receita ou fórmula definida - aliás, o que provavelmente nunca existirá - e que depende muito mais de um encontro aberto e genuíno entre profissionais e usuários(as) do que uma prescrição sobre o que fazer. O cuidado a ser tomado é quanto aos rumos dessas mudanças, para que o melhor caminho não seja somente aquele indicado pelos(as) profissionais. Para Fernandes (2006), em uma perspectiva ética que prime pela autonomia, cidadania e protagonismo do(a) usuário(a), o(a) profissional deve se abster de qualquer tentativa de controle, respeitando a diversidade e alteridade das pessoas. Já quando o(a) profissional consegue fomentar essa mudança sem pretensões normativas, como indica Nery (2009), abre-se uma importante via de resgate e fortalecimento de múltiplas subjetividades e intersubjetividades que poderiam estar minimizadas devido à privação das necessidades básicas, passando então o(a) psicólogo(a) a dar voz e escuta qualificada a esses sujeitos.

Esse processo de mudança a partir da perspectiva relacional entre profissionais e usuários(as) pode acontecer não só na vida dos usuários, mas também para a psicologia enquanto ciência e profissão. Aproximando-se da perspectiva do outro, da realidade e das necessidades da "vida vivida", torna-se possível seu avanço não só teoricamente, mas também ética e politicamente, o que parece ser fundamental para a atuação no SUAS.

\section{Considerações finais}

Neste artigo foi possível visibilizar e problematizar a existência de uma representação social relacional, em que é dado destaque para as relações entre profissionais e usuários(as). Quando adotam essa perspectiva relacional, os(as) profissionais abrem a possibilidade para modos de fazer psicologia que incluem a dimensão do outro, ou seja, a dimensão ético-política. Assim, ao invés de práticas agenciadoras de subjetividades, pode-se ter uma psicologia questionadora de suas próprias concepções e ações, vendo nos(as) usuários(as) possibilidades de relações e parcerias micro-políticas de transformação.

Com isso, a psicologia assume o compromisso social de uma prática comprometida com a realidade do país e os direitos humanos, problematizando e propondo ações a partir de compreensões críticas sobre aspectos sociais, econômicos, culturais e políticos (CFP, 2011). A concepção relacional tem a ver também com as próprias definições da Política Nacional de Assistência Social (PNAS) (BRASIL, 2004), base para o trabalho no SUAS. Logo no seu início, há a adoção da proposta de "uma visão social inovadora [...] pautada na dimensão ética de incluir 'os invisíveis', os transformados em casos individuais, enquanto de fato são parte de uma situação social coletiva" (BRASIL, 2004, p. 10), o que evidencia o quanto o texto está em consonância com os achados deste artigo.

Assim, o que se conclui é que ao adotar uma perspectiva relacional, os(as) profissionais concebem os(as) usuários(as) em toda sua complexidade e contradições: pertencentes a um contexto histórico, social e cultural, produtos e produtores dessa realidade. Embora se reconheçam neles(as) características que remetem ao assistencialismo, compreende-se a importância do contexto onde estão inseridos para tal situação, sem negar a potência subjetiva de transformação desses sujeitos e desses contextos a partir dos encontros gerados pelo SUAS no mundo da vida cotidiano. É isso que pode possibilitar que profissionais e usuáris(as) possam, juntos, colocar mudanças em movimento.

Isso evidencia também o quanto existem modos diferentes de se operacionalizar a psicologia na política de assistência social, o que acaba dependendo em grande parte das representações sociais adotadas e compartilhadas pelos(as) profissionais. Assim, tem-se tanto uma psicologia capaz de individualizar, culpabilizar e visar o ajustamento e a normatização dos(as) usuários(as), quanto uma psicologia que aposta nas relações, nas possibilidades diversas de vida e modos múltiplos de singularização dos sujeitos, como visto aqui. 


\section{Referências}

BAUER, M. W.; AARTS, B. A construção de um corpus: um princípio para a coleta de dados qualitativos. In: BAUER, M. W.; GASKELL, G. (Org.). Pesquisa Qualitativa com texto, imagem e som: um manual prático. 7. ed. Petrópolis, RJ: Vozes, 2008. p. 39-63.

BRASIL. Ministério do Desenvolvimento Social e Combate à Fome. Politica Nacional de Assistência Social. Brasília: MDS, 2004. Disponível em: <http://www.mds.gov.br/webarquivos/ publicacao/assistencia_social/Normativas/PNAS2004.pdf>. Acesso em: 20 jun. 2013.

BRASIL. Ministério do Desenvolvimento Social e Combate à Fome. Censo SUAS 2010. Brasília: MDS, 2010. Disponível em: <http://prattein.com.br/home/images/stories/Assistncia Social/CensoSuas.pdf $>$. Acesso em: 20 jun. 2013.

BRASIL. Ministério do Desenvolvimento Social e Combate à Fome. Censo SUAS 2009 - CRAS. Brasília: MDS, 2011.

BRASIL. Ministério do Desenvolvimento Social e Combate à Fome. O Serviço de Proteção e Atendimento Integral à Família: PAIF, segundo a Tipificação Nacional de Serviços Socioassistenciais - volume 1. Brasília: MDS, 2012.

CONSELHO FEDERAL DE PSICOLOGIA. Referências técnicas para atuação do(a) psicólogo(a) no CRAS-SUAS. Brasília, DF: CFP, 2008.

CONSELHO FEDERAL DE PSICOLOGIA. Como os psicólogos e psicólogas podem contribuir para avançar o Sistema Único de Assistência Social (SUAS): informação para gestoras e gestores. Brasília, DF: CFP, 2011.

COUTO, B. R. et al. O Sistema Único de Assistência Social no Brasil: uma realidade em movimento. São Paulo: Cortez, 2010.

FÁVERO, E. T. Questão social e perda do poder familiar. São Paulo: Veras, 2007.

FERNANDES, I. Dialética da instrumentalidade: abordagem grupal e familiar na perspectiva da assistência social. In: MENDES, J. M. R.; PRATES, J. C.; AGUINSKY, B. (Org.). Capacitação sobre PNAS e SUAS: no caminho da implantação. Porto Alegre: EDIPUCRS, 2006. p. 135-151.

GASKELL, G.; BAUER, M. W. (Org.). Para uma prestação de contas pública: além da amostra, da fidedignidade e da validade. In:_. Pesquisa Qualitativa com texto, imagem e som: um manual prático. 7. ed. Petrópolis, RJ: Vozes, 2008. p. 470-490.

GILL, R. Análise de discurso. In: BAUER, M. W.; GASKELL, G. (Org.). Pesquisa Qualitativa com texto, imagem e som: um manual prático. 7. ed. Petrópolis, RJ: Vozes, 2008. p. 244-270.

GUARESCHI, P. A. Psicologia Social Crítica - como prática de libertação. 4. ed. Porto Alegre: EDIPUCRS, 2004.

HILLESHEIM, B.; CRUZ, L. R. Do território às políticas públicas: governamento, práticas psicológicas e busca ativa no CRAS. In: CRUZ, L. R.; GUARESCHI, N. (Org.). O psicólogo $e$ as políticas públicas de assistência social. Petrópolis, RJ: Vozes, 2012. p. 91-105.

JOVCHELOVITCH, S. Os Contextos do saber: representações, comunidade, cultura. Petrópolis, RJ: Vozes, 2008.

LASTA, L. L.; GUARESCHI, N. M. F.; CRUZ, L. R. A Psicologia e os Centros de Referência em Assistência Social: problematizações pertinentes. In: CRUZ, L. R.; GUARESCHI, N. (Org.). O psicólogo e as políticas públicas de assistência social. Petrópolis, RJ: Vozes, 2012. p. 52-65.
MACEDO, J. P. et al. O psicólogo brasileiro no SUAS: quantos somos e onde estamos? Psicologia em Estudo, Maringá, v. 16, n. 3, p. 479-489, 2011.

MARTIN-BARÓ, I. O papel do psicólogo. Estudos de Psicologia, [S.1.], v. 2, n. 1, p. 7-27, 1996.

MIOTO, R. C. T. Novas propostas e velhos princípios: a assistência às famílias no contexto de programas de orientação e apoio sociofamiliar. In: SALES, M. A.; MATOS, M. C; LEAL, M. C. (Org.). Política social, família e juventude: uma questão de direitos. 6. ed. São Paulo: Cortez, 2010. p. 43-59.

NERY, V. B. O trabalho de assistentes sociais e psicólogos na Política de Assistência Social: saberes e direitos em questão. 2009. Tese (Doutorado)-Pontifícia Universidade Católica de São Paulo, São Paulo, 2009.

PEREIRA, V. T.; GUARESCHI, P. Representações Sociais da psicologia sobre os usuários do CRAS: culpabilização dos sujeitos em situação de vulnerabilidade social. Revista Diálogo, Canoas, n. 26, p. 09-24, 2014.

SAWAIA, B. (Org.). Introdução: exclusão ou inclusão perversa. In: _. As artimanhas da exclusão. 12 ed. Petrópolis, RJ: Vozes, 2012. p. 7-15.

XIMENES, V. M.; PAULA, L. R. C. de; BARROS, J. P. P. Psicologia comunitária e política de assistência social: diálogos sobre atuações em comunidades. Psicologia: Ciência $e$ Profissão, Brasília, v. 29, n. 4, p. 686-699, 2009.

Recebido em: 9 de julho de 2013 Aceito em: 28 de outubro de 2015 